\title{
ROLE OF 2D DOPPLER ULTRASOUND ON THE DAY OF EMBRYO TRANSFER IN PREDICTING PREGNANCY IN ICSI
}

\author{
Samar Ramzy Ragheb ${ }^{*}$, Sherine Mohamed Sharara ${ }^{*}$,Mohamed Sayed Aly ${ }^{* *}$, \\ Mohamed Mahmoud El-Sherbiny ${ }^{* *}$, Hayam Fathy Mohammad ${ }^{* *}$, and \\ Hussam Afify Badran ${ }^{* *}$
}

* Department of radiodiagnosis and **Department of Obstetrics and Gynecology, Faculty of Medicine, Ain Shams University Hospital, EGYPT

Corresponding :

Samar Ramzy Ragheb

Mobile: 01003568254

E mail:

doc_mina2004@yahoo.com

Received: 9/7/2019

Accepted: 8/8/2019

\begin{abstract}
:
Background: Endometrium examination by Ultrasound is commonly used to assess the endometrial receptivity during in vitro fertilization (IVF) treatment.
\end{abstract}

Aim of the work: To evaluate the role of pulsatility index (PI) of uterine artery blood flow during IVF-ET cycles in prediction of pregnancy rate.

Patients \& Methods: A prospective study was conducted at Maternity Hospital of Ain Shams University in cooperation with the department of Radiodiagnosis. It included 400 females, diagnosed as infertility for ICSI (Intracytoplasmic sperm injection) trial. The uterine artery parameters (PI \& RI) and endometrial thickness were measured by $2 D$ Doppler ultrasound on the day of embryo transfer. ICSI_ET led to 193 clinical pregnancies with multiple pregnancies in 38 cases. The pregnancy rate was $48.25 \%$ with application of the Gonadotropin-releasing hormone (GnRH) long protocol, and the implantation rate was 30\% of ( $N=120$ cases). The 193 intrauterine pregnancies were classified as the pregnant group (P); the other 207 cases were classified as the non pregnant group (NP).

Results: There was statistically significant difference as regards pregnancy outcome in the sub-endometrial blood flow PI ( $p$ value $0.01)$ which is lower in pregnant group $(P)$ than non pregnant ones (NP). However there was no statistically significant difference as regards the mean midcycle endometrial thickness in pregnant group $(P)$ were 11.35 and that of non pregnant group (NP) was 10.8 with $P$ value (0.62).

Conclusion: Midluteal phase of females with unexplained infertility have been shown to be of some value in predicting pregnancy rates.

Keywords: Uterine artery, PI, sub-endometrial blood flow, 2D Doppler ultrasound, Infertility, ICSI

\section{INTRODUCTION:}

During the menstrual cycle, the endometrium has no adhesive quality until the implantation window phase, during which for a very short period, the implantation of gestational sacs was allowed. This property is called endometrial receptivity ${ }^{[1]}$. Endometrial receptivity has been for a long time the backbone in the field of assisted reproduction because the synchronous changes of the endometrium with embryonic development are the essence for embryonic implantation ${ }^{[2]}$. 


\section{Samar Ramzy Ragheb, et al.,}

Good maternal conditions and embryo status are principal for successful implantation. Problems that can develop from the maternal side include abnormal uterine anatomy, maternal general conditions, and a non-receptive endometrium; all can have unfavorable effects on the crossconnection between both sides; embryo and the endometrium ${ }^{[3]}$. The endometrium is critical for a successful implantation in communication with the embryo. Endometrial embryo interactions can be altered if the embryo is deformed, which can result from either paternal sperm factors or maternal oocyte abnormalities ${ }^{[4]}$.

To make an excellent endometrialembryo interaction, the endometrium must become thicker, with richer vascularity. Endometrial blood flow reflects uterine receptivity as the endometrium is the site of embryonic implantation ${ }^{[5]}$. During in vitro fertilization (IVF) and embryo transfer cycles (IVF-ET), implantation is a crucial factor of success or failure. Up to $65 \%$ of implantation failures are estimated to be caused by defects in endometrial receptivity ${ }^{[6]}$. Efforts have been made to evaluate endometrial receptivity in endometrial and sub-endometrial blood supplies, especially during intrauterine insemination and IVF-ET cycles ${ }^{[7]}$.

Previous studies discussed endometrial receptivity were mainly focused on histopathology of the endometrium, presented as endometrial

dating by "Noyes et al,1975" dating ${ }^{[8]}$, or searching for the receptors for estrogen, progesterone and other known factors related to endometrial receptivity. However, the diagnostic methods used for the above studies were invasive, time wasting, and entailed intrauterine biopsy were not accepted by patients, because they were concerned about subsequent miscarriage, and thus lost their value in guiding the assessment of endometrial receptivity, in those who wanted to be pregnant in this cycle $^{[2]}$.

Endometrium examination by Ultrasound is commonly used as a non-invasive procedure to assess the endometrial receptivity during in vitro fertilization (IVF) treatment. In which a significant endometrial blood supply is usually considered to be a mandatory requirement for implantation success and therefore, the assessment of endometrial blood flow (EBF) in IVF treatment has attracted a lot of attention in recent studies ${ }^{[9]}$.

Ultrasound indices including endometrial thickness, endometrial pattern, endometrial volume, Doppler study of uterine arteries and endometrial blood flow have been used to assess endometrial receptivity during IVF treatment. Assessment of endometrial blood flow adds a physiological aspect to the anatomical ultrasound parameters. However, conflicting results are reported with regard to their role in the prediction of pregnancy in IVF treatment ${ }^{[10]}$. Some investigators have supposed the existence of a correlation between the extent of endometrial development determined by ultrasound and the possibility of embryo implantation, whereas others do not consider the pattern and thickness of the endometrium to be of critical importance for the prediction of embryo implantation ${ }^{[11]}$.

Many studies in the literature differed in patients' demographic data, timing of ultrasound examination and the selection of the sub-endometrialregion ${ }^{[9]}$.A study was conducted to determine the best timing to do Doppler ultrasound as a non-invasive procedure to assess uterine receptivity in order to make the best prediction of the pregnancy outcome. It was found that Doppler ultrasound should be done on the same day of human chorionic gonadotropin (HCG) administration to get the best sensitivity and specificity ${ }^{[\mathbf{1 2}]}$. 


\section{AIM OF THE WORK:}

To evaluate the role of pulsatility index (PI) of uterine artery blood flow (UABF), sub-endometrial blood flow and endometrial thickness in the midluteal phase during IVFET cycles in prediction of pregnancy rate.

\section{PATIENTS AND METHODS:} study.

Study design: Prospective clinical

Setting: The study was conducted at the Assisted Reproduction unit - Maternity Hospital - Ain shams university in cooperation with department of Radiodiagnosis.

\section{Inclusion criteria:}

1- Age: 20 - 35 years old.

2- Regular cycles.

3- Primary or secondary infertility.

4- Various etiologies of infertility (Male, Tubal, Polycystic ovary, Unexplained factors)

5- Endometriosis.

6- An informed consent was obtained for study participation.

\section{Exclusion criteria:}

1- Age less than 20 years old or more than 35 years old.

2- Major medical disorders and mental diseases that are contraindications for pregnancy and childbirth. Congenital malformations and acquired deformities of the uterine cavity that make embryo implantation or pregnancy impossible (e.g. septate uterus, Asherman syndrome).

3- Ovarian tumors.

4- Benign tumors of uterus requiring surgery.
5- Acute pelvic inflammatory diseases.

7- Malignancy of any location

\section{Study methods and steps:}

- 400 females from Assisted Reproduction Unit were enlisted in the study group.

- According to inclusion and exclusion criteria patients who meet the inclusion criteria will be enlisted.

- enlisted females filled in a written consent.

- Long protocol using Gonadotropinreleasing hormone $(\mathrm{GnRH})$ analog for pituitary suppression followed by stimulation using human menopausal gonadotropin (HMG).

2D Doppler ultrasound examination was done for all females on the day of Embryo Transfer at the department of radiodiagnosis. After a true longitudinal view of the uterus is obtained, the ultrasonic findings will be classified according to:

1- The morphology of the endometrium:

- Type A: triple-line or multi-layered type.

- Type B: isoechoic type.

- Type C: hyperechoic type.

2- Endometrial thickness: Double thickness of the endometrium will be measured (maximum distance between each myometrial/endometrial interface through the longitudinal axis of the uterus).

3- Uterine artery blood flow: Using 2D Doppler, flow velocity wave forms will be obtained from the ascending main branch of the uterine artery on the right and left side of the cervix before it enters the uterus.

4- Sub-endometrial blood flow: The zones of vascular penetration into the subendometrial and endometrial regions is defined as: Zone I: the sub-endometrial 


\section{Samar Ramzy Ragheb, et al.,}

zone. Zone II: the outer hyperechogenic zone and Zone III: the inner hypoechogenic zone.

\section{RESULTS:}

This study included 400 women who met the inclusion criteria. The aim of the study was to assess the predictive flow, endometrial thickness and pattern by 2D Doppler ultrasound on the day of embryo transfer and its implement on implantation and getting pregnancy.

ICSI_ET led to 193 clinical pregnancies with multiple pregnancies in 38 cases. The pregnancy rate was $48.25 \%$ with application of the GnRH long protocol, and the implantation rate was $30 \%$ of $(\mathrm{N}=120$ cases). The 193 intrauterine pregnancies were classified as the pregnant group; the other 207 cases were classified as the nonpregnant group.

\section{Characteristics of the study group:}

The age of studied group (Table 1) ranged from 19 years and 37 years with a mean of 32.5 years and the body mass index (BMI) ranged from22 to 46 with a mean of 33.5 , while the mean duration of marriage is 7.5 years and the mean duration of infertility is 7.5 years. Mean serum FSH is 6.39, mean serum LH is 5.4, mean serum TSH is 2.225 , mean serum prolactin is 12.25 and mean serum E2 is 49 .

Table (1): Description of quantitative variables

\begin{tabular}{|l|c|c|c|}
\hline Variable & Range & Mean & S.D \\
\hline Age(Yrs) & $19-37$ & 32.5 & \pm 3.47 \\
\hline BMI & $22-46$ & 33.5 & \pm 4.11 \\
\hline Duration of marriage(Yrs) & $1-16$ & 7.5 & \pm 0.75 \\
\hline Duration of infertility(Yrs) & $1-16$ & 7.5 & \pm 0.74 \\
\hline FSH(mIU/ml) & $3.9-16$ & 6.395 & \pm 0.8138 \\
\hline $\mathrm{LH}(\mathrm{mIU} / \mathrm{ml})$ & $2-14$ & 5.4 & \pm 0.949 \\
\hline TSH $(\mathrm{mIU} / \mathrm{ml})$ & $1-5.4$ & 2.225 & \pm 0.37 \\
\hline Prolactin(ng/ml) & $4-51$ & $12-25$ & \pm 3.7 \\
\hline E2 & $15-100$ & 49 & \pm 19.7 \\
\hline
\end{tabular}

The chemical and clinical pregnancy rates were minimally different (Table 2); $47.5 \%$ for chemical pregnancy results and $46.25 \%$ for the actual clinical pregnancy outcome.

Table (2): Pregnancy outcome among studied group:

\begin{tabular}{|l|c|l|}
\hline & Frequency (n) & Percentage (\%) \\
\hline $\begin{array}{l}\text { Chemical pregnancy outcome } \\
\text { +ve }\end{array}$ & 190 & $47.5 \%$ \\
-ve & 210 & $52.5 \%$ \\
\hline Clinical pregnancy outcome & 193 & \\
$\quad+\mathrm{ve}$ & 207 & $56.25 \%$ \\
-ve & $53.75 \%$ \\
\hline
\end{tabular}

The characteristics of the study subjects are shown in the two tables (3\&4) as regards the pregnancy outcome. There was no statistically significant difference between the two groups (pregnant group and non- pregnant group) as regards age $\mathrm{p}$ value 0.068 , BMI $p$ value 0.53 ,or the LH level $p$ value $0.156, \mathrm{E} 2 \mathrm{p}$ value 0.75 and TSH levels $\mathrm{p}$ value 0.52 . 
Table (3): The characteristics of the study subjects regarding their BMI, duration of marriage and infertility and hormonal profile.

\begin{tabular}{|l|c|c|c|}
\hline & $\begin{array}{c}\text { Pregnancy. } \\
+ \text { Ve (n=193) } \\
\text { (Pregnant group) } \\
\text { Mean + S.D }\end{array}$ & $\begin{array}{c}\text { Outcome } \\
- \text { Ve (n=207) } \\
\text { (non-pregnant group) } \\
\text { Mean + S.D }\end{array}$ & P value \\
\hline Age(Yrs) & $25.6 \pm 6.03$ & $29 \pm 5.75$ & 0.068 \\
\hline BMI & $28.03 \pm 5.89$ & $38.8 \pm 5.7$ & 0.53 \\
\hline Durationof marriage (Yrs) & $4.4 \pm 3.03$ & $8.23 \pm 2.043$ & $0.04^{*}$ \\
\hline Duration of infertility (Yrs) & $4.6 \pm 3.8$ & $6.7 \pm 3.03$ & $0.0399^{*}$ \\
\hline FSH (mIU/ml) & $5.546 \pm 1.159$ & $7.19 \pm 1.12$ & $0.048^{*}$ \\
\hline LH $(\mathrm{mIU} / \mathrm{ml})$ & $5.347 \pm 1.359$ & $5.5 \pm 1.313$ & 0.156 \\
\hline TSH $(\mathrm{mIU} / \mathrm{ml})$ & $2.2 \pm 0.527$ & $2.24 \pm 0.512$ & 0.52 \\
\hline Prolactin/ng/ml) & $10.637 \pm 5.33$ & $14.39 \pm 5.15$ & $0.001^{*}$ \\
\hline E2 $(\mathrm{Pg} / \mathrm{ml})$ & $45.6 \pm 13.87$ & $38.67 \pm 13.37$ & 0.75 \\
\hline
\end{tabular}

(*) significant $\mathrm{p}$ value result

While it is statistically significant regarding duration of marriage $\mathrm{p}$ value 0.04 and duration of infertility 0.0399 , FSH profile $\mathrm{p}$ value 0.048 and prolactin level $\mathrm{P}$ value 0.001 .

Type of infertility wasn't statistically different $p$ value 0.72 or cause of infertility regarding male factor $\mathrm{p}$ value 0.81 , or ovarian factor, $p$ value 0.83 , while it is statistically significant as regards unexplained causes $\mathrm{p}$ value 0.0095 , ovarian and male, $\mathrm{p}$ value 0.0041 and tubal factor $\mathrm{p}$ value 0.0039 .

There was no statistical significance between pregnant and non-pregnant group as regards if previous ICSI was done, number of embryos transferred or quality of embryos transferred.

Table (4): The characteristics of the study subjects regarding their infertility profile

\begin{tabular}{|c|c|c|c|}
\hline & $\begin{array}{c}\text { Pregnancy. } \\
+ \text { Ve }(\mathrm{n}=193) \\
\text { (pregnant group) } \\
\mathrm{N} \%\end{array}$ & $\begin{array}{c}\text { Outcome } \\
-\mathrm{Ve}(\mathrm{n}=207) \\
\text { (non-pregnant group) } \\
\mathrm{N} \%\end{array}$ & $\mathrm{P}$ value \\
\hline $\begin{array}{l}\text { Type of infertility } \\
\text { 1ry } \\
\text { 2ry }\end{array}$ & $\begin{array}{c}17390 \\
2010 \\
\end{array}$ & $\begin{array}{c}16680.2 \\
4119.8 \\
\end{array}$ & 0.72 \\
\hline $\begin{array}{l}\text { Cause of infertility } \\
\text { Male } \\
\text { Unexplained } \\
\text { Ovarian + Male } \\
\text { Ovarian } \\
\text { Tubal } \\
\end{array}$ & $\begin{array}{c}7739.9 \\
7337.8 \\
115.7 \\
3116 \\
10.6 \\
\end{array}$ & $\begin{array}{c}10349.8 \\
209.6 \\
3818.4 \\
167.7 \\
3014.5 \\
\end{array}$ & $\begin{array}{c}0.81 \\
0.0095 * \\
0.0041 * \\
0.83 \\
0.0039 *\end{array}$ \\
\hline $\begin{array}{l}\text { Previous ICSI } \\
\text { Yes } \\
\text { No } \\
\end{array}$ & $\begin{array}{l}9448.7 \\
9951.3 \\
\end{array}$ & $\begin{array}{c}9951.3 \\
10848.7 \\
\end{array}$ & 0.9 \\
\hline $\begin{array}{c}\text { Number of embryos transferred } \\
1 \\
2 \\
3 \\
\end{array}$ & $\begin{array}{l}5830.1 \\
7739.8 \\
5839.8 \\
\end{array}$ & $\begin{array}{l}8239.6 \\
4320.3 \\
8239.6 \\
\end{array}$ & $\begin{array}{l}0.77 \\
0.63 \\
0.77 \\
\end{array}$ \\
\hline $\begin{array}{l}\text { Quality of embryos transferred } \\
\text { Grade } 1 \\
\text { Grade } 2 \\
\end{array}$ & $\begin{array}{c}19198.9 \\
21.1 \\
\end{array}$ & $\begin{array}{c}19694.6 \\
115.4\end{array}$ & 0.75 \\
\hline
\end{tabular}

$\left(^{*}\right)$ significant $\mathrm{p}$ value result 


\section{Samar Ramzy Ragheb, et al.,}

Table (5): Comparison between pregnant and non-pregnant group as regard ultrasound and Doppler parameters

\begin{tabular}{|l|c|c|c|}
\hline & $\begin{array}{l}\text { Pregnancy. } \\
\text { +Ve }(\mathrm{n}=193) \\
\text { MeanS.D }\end{array}$ & $\begin{array}{l}\text { Outcome } \\
- \text { Ve(n=207) } \\
\text { MeanS.D }\end{array}$ & P value \\
\hline Endometrial thickness & 11.352 .39 & 10.82 .31 & 0.61 \\
\hline Sub-endometrial PI & $0.91 \pm 0.2$ & $0.98 \pm 0.294$ & $0.01 *$ \\
\hline Sub-endometrial RI & $0.863 \pm 0.238$ & $0.867 \pm 0.23$ & 0.31 \\
\hline Sub-endometrial S/D & $2.4 \pm 0.5$ & $2.819 \pm 0.489$ & 0.38 \\
\hline Average uterine art. PI & $2.09 \pm 0.69$ & $2.1 \pm 0.76$ & 0.22 \\
\hline Average uterine art. RI & $0.987 \pm 0.33$ & $1.33 \pm 0.324$ & 0.11 \\
\hline Average uterine art, S/D & $6.72 \pm 2.1$ & $11.23 \pm 9.05$ & 0.159 \\
\hline
\end{tabular}

(*) significant $\mathrm{p}$ value result

Table (6): Correlation between implantation rate and doppler parameters:

\begin{tabular}{|l|c|c|}
\hline & Implantation R & Rate P \\
\hline Sub-endometrial PI & 0.081 & 0.695 \\
\hline Sub-endometrial RI & -0.222 & 0.188 \\
\hline Sub-endometrial S/D & -0.411 & 0.05 \\
\hline Average uterine art. PI & 0.138 & 0.522 \\
\hline Average uterine art. RI & -0.062 & 0.766 \\
\hline Average uterine art. S/D & 0.149 & 0.368 \\
\hline
\end{tabular}

(Table $5 \& 6$ ) demonstrates that there is no statistical difference regarding different Doppler parameters in correlation with implantation rate except with subendometrial PI (Fig. 1, 2 \& 3). Grouping of the endometrial thickness into three groups was done. The endometrial thickness that showed significance is between $9 \mathrm{~mm}$ and
$12 \mathrm{~mm}$ with mean of $10.5 \mathrm{~mm}$ and S.D of + 0.57 ; and $\mathrm{P}$ value of 0.0196 . (Table 7 ) Shows the results of Receiver Operating Characteristics (ROC) curve analysis to explore the discriminant ability of subendometrial PI in predicting pregnancy outcome.

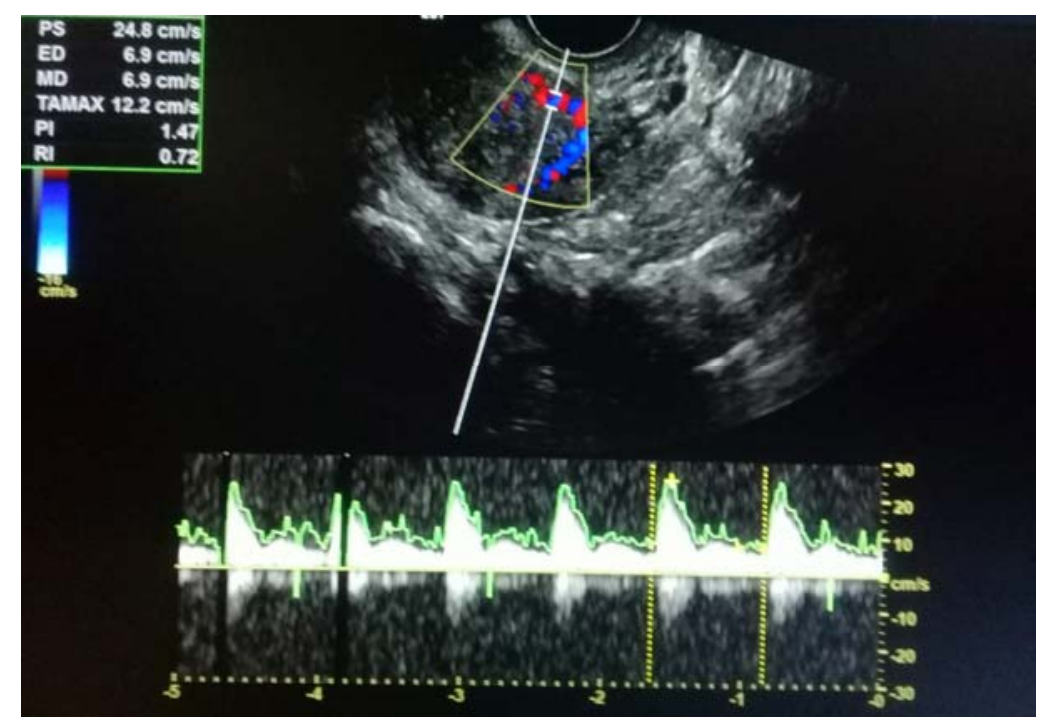

Fig. 1: Normal waveform of the uterine artery with low pulsatility index (1.47) 


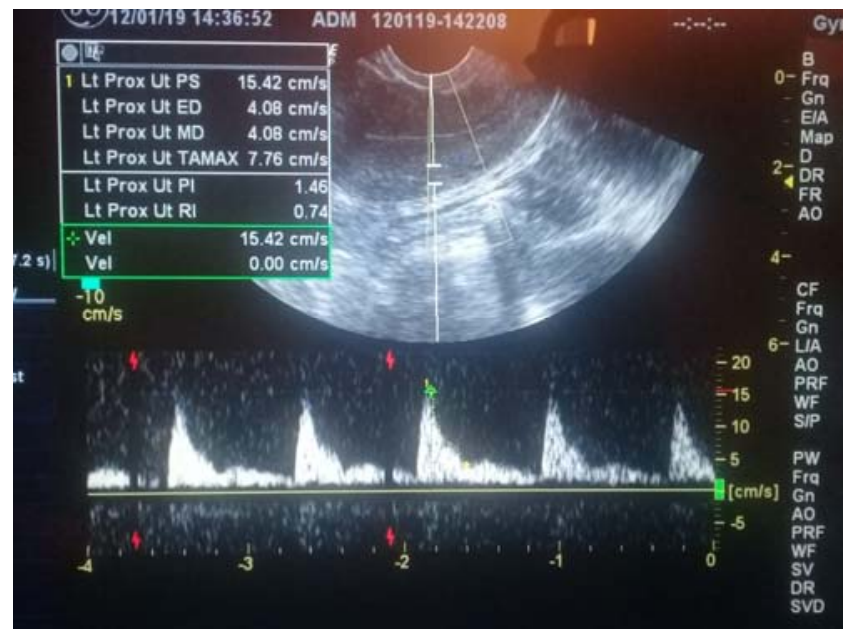

Fig. 2: Normal waveform of the uterine artery with low pulsatility index (1.46)

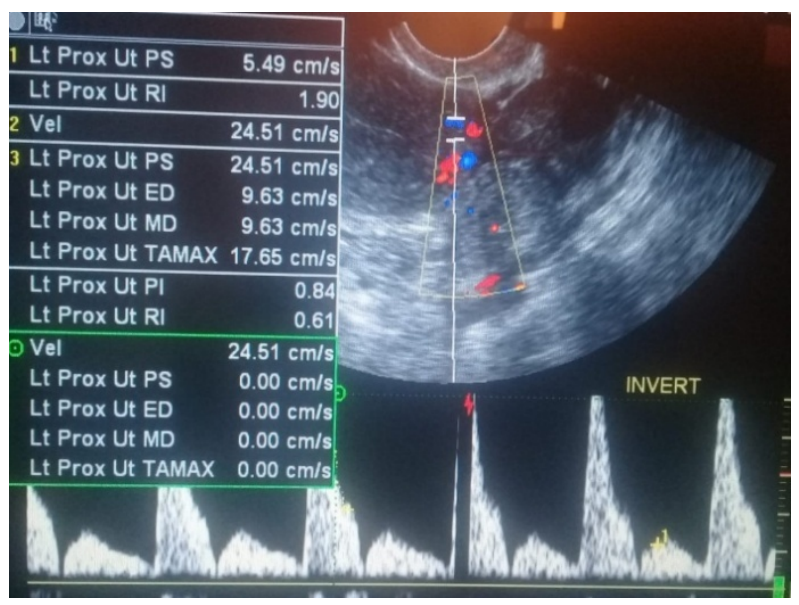

Fig. 3: Normal waveform of the uterine artery with low pulsatility index (0.84)

Table (7): ROC curve of sub endometrial PI sensitivity on Y curve, Specificity on X curve.

\begin{tabular}{|l|c|}
\hline \multicolumn{1}{|c|}{ ROC curve analysis } & Measures \\
\hline Area under the ROC curve (AUC) & 0.750 \\
Standard Error & 0.073 \\
95\% Confidence interval & 0.4970 .760 \\
\hline Z statistic & 2.269 \\
significance level P (Area $=0.5)$ & 0.031 \\
\hline Youden index j & 0.411 \\
cut -off criterion & $<1.3$ \\
\hline Sensitivity & 91.50 \\
95\% CI & $69.0-98.5$ \\
\hline Specificity & 50.2 \\
$95 \%$ CI & $33.0-70.2$ \\
\hline +LR & 1.7 \\
95\% CI & $1.6-2.6$ \\
\hline LR & 0.29 \\
95\% CI & $0.12-0.73$ \\
\hline +PV & 61.3 \\
$95 \%$ CI & $44.6-77.2$ \\
\hline PV & 84.4 \\
$95 \%$ CI & $60.3-95.5$ \\
\hline
\end{tabular}




\section{DISCUSSION}

Infertility is a common problem, in which $20 \%$ of married population is involuntarily childless. In recent years, there has been an increase in public attention about infertility and reproductive medicine updates, which has gone some way to reduce both the shame of infertility and the hesitation of couples to seek advice ${ }^{[13]}$.

Regardless of numerous evolutions in IVF and ICSI, the implantation rate of the replaced embryos remains low, and it has been estimated that up to $84.5 \%$ of replaced embryos failed to be implanted ${ }^{[14]}$.

Many approaches to raise the implantation rate have been proposed and practiced. These include ${ }^{[14]}$ improvement of embryo transfer technique, ${ }^{[15]}$ improvement of endometrial receptivity, and improvement of the embryo to capacity implantation ${ }^{[14]}$.

Now we search in our study the reasonability of depending on sonographic results on choosing day of embryo transfer.

The implantation capacity of good quality embryos remains low during in vitro fertilization - embryo transfer (IVF-ET) treatment, despite advances in ovarian stimulation protocols, the method of assisted fertilization and improved culture environment; implantation failure remains an unsolved problem in reproductive medicine ${ }^{[15]}$. Successful implantation based on a close communication between the (blastocyst) and the receptive (endometrium). Numerous approaches have been developed to assess endometrial receptivity, such as the histologic dating of an endometrial biopsy [14], endometrial cytokines in uterine flushing, the genomic study of a timed endometrial biopsy or more commonly a non-invasive ultrasonography of the endometrium.

Uterine artery Doppler represents a noninvasive procedure for the assessment of uterine perfusion. Many reports suggested that uterine perfusion is among the many factors involved in regulating endometrial receptivity, thereby playing a valuable role in the regulation of female fertility and a successful pregnancy ${ }^{[16]}$.

Many studies found that the area in between the myometrium and endometrium acts as a border which plays an important role in endometrial receptivity, this area can be seen as a thin low-echo layer ${ }^{[2]}$. The appearance of the endometrium in the ultrasound examinations changes throughout the menstrual cycle. in which in the Proliferative phase, the texture of endometrium is hypo-echoic with a well-defined central echogenic line. While in the secretory phase, this texture becomes hyper-echogenic and the central echogenic line cannot be visualized $^{[17]}$.

Transvaginal ultrasound was used to determine follicular maturation, mid cycle endometrial thickness, mid cycle echogenic pattern, and midluteal endometrial homogeneity.

This study included 400 women, diagnosed as infertility for ICSI trial.

According to the results of midluteal endometrium, the study group was divided into two subgroups depending on homogeneity. The first subgroup included patients proved to have homogeneous triphasic endometrium that has amounted to 343 patients $(85.75 \%)$. The second subgroup included patients proved to have isoechoic endometrium, which has amounted to 31 patients $(7.75 \%)$ and the third group included patients who demonstrated hyperechoic endometrium by sonography and represented 26 patients $(0.65 \%)$.

In our study, there was significant higher pregnancy rate in the subgroup with a midluteal homogeneous triphasicpattern( $\mathrm{P}$ $0.001)$. And to lesser significance index the isoechoic pattern ( $\mathrm{P}$ value 0.048). While hyperechoic pattern show no significance.

In our study, the mean midcycle endometrial thickness in pregnant cases was 
11.35 and that of non-pregnant cases 10.8 with $P$ value $(0.62)$.

It was constant with ${ }^{[18]}$ because they were found that there is no significant difference in midcycle endometrial thickness and ${ }^{[19]}$ found there was similar pregnancy rates in patients treated with clomiphene citrate with an endometrial thickness $<6$ and $>6 \mathrm{~mm}$.

It was constant with ${ }^{18 \text { ] }}$ because they were found that there is no significant difference in midcycle endometrial thickness and ${ }^{[19]}$ found there was similar pregnancy rates in females treated with clomiphene citrate with an endometrial thickness $<6$ and $>6 \mathrm{~mm}$.

The pulsatility index (PI) of uterine artery has been known to decline progressively during the luteal phase during which implantation takes place. These changes differ from those observed in the upper extremity radial artery (control vessel) suggesting autonomy of regional pelvic and systemic hemodynamic adaptations ${ }^{[18]}$.

It is commonly accepted that pulsatility index (PI) values may be classified as; low, medium, and high, in the ranges of 0.00 1.99, 2.00-2.99, and 3, respectively; studies from Assisted Reproductive Therapy (ART) exhibit the highest pregnancy rate when PI values were $<2.5$, Although no studies have obtained implantation when the PI values were $>3$ or when diastolic flow is not noted in the Doppler waveform ${ }^{[16]}$.

Zaidi et al. ${ }^{[20]}$ analyzed endometrial thickness, endometrial morphology, and presence or absence of sub-endometrial or intra-endometrial color flow in 96 infertile patients under going IVF treatment. The results of the study obtained on the day of HCG administration were related to the pregnancy rates. The overall pregnancy rate was $32.3 \%$, and there was no remarkable difference between pregnant $(\mathrm{P})$ and nonpregnant groups (NP) regarding endometrial thickness. The pregnancy rates were not significantly different for different morphological patterns of endometrium ( $p>$ 0.05 ). The absence of endometrial blood flow was associated with the failure of implantation $(\mathrm{p}<0.05)^{[20]}$.

Using a pulsatility index (PI) upper limit of 3.0 by Steer et al. ${ }^{[21]}$ the indices of uterine artery blood flow had a high negative predictive value (NPV) and sensitivity (88$100 \%$ and $96-100 \%$, respectively) with a relatively higher range of positive predictive value (PPV) and specificity (44-56\% and 13$35 \%$, respectively) for occurrence of a successful pregnancy .

Doppler indices of uterine arteries may not reflect the actual endometrial blood flow as the major partition of the uterus is the myometrium and there is collateral circulation between ovarian and uterine vessels. Regarding the endometrial blood flow measured by 2D ultrasound, it comes from the radial artery, which passes through the junction between endometrium and myometrium and divides to form the basal arteries that nourish the basal part of the endometrium, and the spiral arteries that continue up towards the endometrium ${ }^{[21]}$.

It is widely accepted that a sufficient endometrial blood supply is required for conception to occur following embryo transfer as a part of assisted reproduction treatment (ART). In contrast to that, it may be that a period of relative endometrial ischemia and hypoxia associated with the periovulatory decline in estradiol level is an important factor of endometrial receptivity $^{[22]}$.

There is still no agreement for the timing of the ultrasound examination for evaluating endometrial receptivity in ICSI treatment. It may be much better to measure sub-endometrial and endometrial blood flow during the follicular phase and early luteal phase to find out the changes in order to define the role of sub-endometrial and endometrial blood flows. 


\section{Samar Ramzy Ragheb, et al.,}

In the present study the effect of age of women on sub-endometrial and endometrial blood flows as measured by Doppler ultrasound during IVF treatment was further examined. It was concluded that age of women had no effect on all sub-endometrial and endometrial 2D Doppler flow indices. This result agrees with the results of $\mathbf{N g}$ et al. ${ }^{[9]}$, who studied the effect of age of females, smoking, types of infertility and parity, causes of infertility and serum level of E2 on Doppler ultrasound during IVF treatment. They found that during ICSI treatment, all the above-mentioned studied factors had no effect on sub-endometrial and endometrial Doppler flow indices measured on the day of hCG injection

Abdel Wahab and colleagues in their study done in 2011, had proved that the presence of good uterine and endometrial blood flow is an important prerequisite for successful implantation and pregnancy continuance as shown by higher uterine artery blood flow resistance and lower endometrial blood flow in recurrent miscarriage cases and those females with unexplained Recurrent pregnancy loss (RPL) may have abnormalities in the endometrial and uterine blood flow ${ }^{[23]}$.

On the other hand Alcázar and RuizPerez reported that no significant differences in Doppler parameters were detected between patients with first-trimester threatened abortion that ended in abortion and control patients ${ }^{[24]}$.

Having a Successful implantation depends on a close relation between the blastocyst and the receptive endometrium ${ }^{[9]}$. It is well-known that uterine receptivity plays a crucial role in the success of assisted reproductive techniques (ART).

Endometrial and Uterine blood flows perform in similar way during the menstrual cycle. Endometrial Doppler should reflect more appropriately the endometrial perfusion and uterine receptivity because the endometrium is the place where implantation occurs. Recently, it has been proposed that the sub-endometrial and endometrial area should be taken as a whole when the uterine perfusion is assessed by color Doppler, since there is no difference between the sub-endometrial and endometrial blood flow regarding the possibility of achieving pregnancy ${ }^{[5]}$.

Wang and coworkers in 2010, had divided in their study 182 females (38 years or younger) undergoing IVF-ET, into 3 groups: Group A $(\mathrm{n}=10)$ with invisible endometrial blood flow; Group B $(\mathrm{n}=82)$ with visible sub-endometrial blood flow and Group C (n = 90) with visible both subendometrial and endometrial blood flow. According to the outcomes of IVF-ET, all cases were re-divided into 3 groups: Group (1) no pregnancy $(\mathrm{n}=92)$; Group (2) intrauterine pregnancy with a live fetus $(\mathrm{n}=$ 70); Group (3) abnormal pregnancy $(n=20$ including embryonic diapauses, biochemical pregnancy, ectopic pregnancy and miscarriage). In Group $\mathrm{C}$, intrauterine pregnancy with live fetus $(62 \%)$ was much higher than that in Group A and B $(0 \%$ and $17 \%, \mathrm{p} \leq 0.001)$. Also, the implantation rate (33\%) was much higher than that in Group $\mathrm{A}$ and $\mathrm{B}(0 \%$ and $19.9 \%, \mathrm{p} \leq$ to 0.001$)$. The Doppler indices were found to be as follows; The pulsatility index (PI) $0.1 \pm 0.2$, resistance index $(\mathrm{RI}) 0.6 \pm 0.1$, and $\mathrm{S} / \mathrm{D}$ of endometrial spiral arteries $2.5 \pm 0.4$ in Group 2, which were much lower than those in Group 1 and Group 3 (p1-2<0.001, p2-3 $<0.05)$. The cases with visible endometrial blood flow had higher clinical pregnancy rates and implantation rates ${ }^{[2]}$.

In our study detected by subendometrial blood flow there's significant relation between Doppler indices on endometrial sonographic evaluation and pregnancy rate outcome. 


\section{Conclusion}

We consider the interpretation and clinical application of our results interesting, and hope that future studies confirm our findings. In this study, we believe that the new 2D markers of endometrial receptivity could be useful for selecting which cycle is more suitable for the transfer of a single embryo and prediction of the outcome of pregnancy.

\section{REFERENCES:}

1. Dominguez F, Remohi J, Pellicer A, Simon C. Human endometrial receptivity: a genomic approach. Reproductive biomedicine online. 2003; 6 (3): 332-8.

2. Wang L, Qiao J, Li R, Zhen X, Liu Z. Role of endometrial blood flow assessment with color Doppler energy in predicting pregnancy outcome of IVF-ET cycles. Reproductive biology and endocrinology : RB\&E. 2010; 8: 122.

3. Simon A, Laufer N. Repeated implantation failure: clinical approach. Fertility and sterility. 2012; 97 (5):1039-43.

4. Kim A, Jung H, Choi WJ, Hong SN, Kim HY. Detection of endometrial and subendometrial vasculature on the day of embryo transfer and prediction of pregnancy during fresh in vitro fertilization cycles. Taiwanese journal of obstetrics \& gynecology. 2014; 53 (3):360-5.

5. Merce LT, Barco MJ, Bau S, Troyano J. Are endometrial parameters by threedimensional ultrasound and power Doppler angiography related to in vitro fertilization/embryo transfer outcome? Fertil Steril. 2008; 89 (1): 111-7.

6. Achache H, Revel A. Endometrial receptivity markers, the journey to successful embryo implantation. Human reproduction update. 2006; 12 (6): 731-46.

7. Revel A. Defective endometrial receptivity. Fertility and sterility. 2012; 97 (5):1028-32.

8. Noyes RW, Hertig AT, Rock J. Dating the endometrial biopsy. American journal of obstetrics and gynecology. 1975; 122 (2): 262-3.
9. Ng EH, Chan CC, Tang OS, Yeung WS, Ho PC. The role of endometrial blood flow measured by three-dimensional power Doppler ultrasound in the prediction of pregnancy during in vitro fertilization treatment. European journal of obstetrics, gynecology, and reproductive biology. 2007;135 (1): 8-16.

10. Singh N, Bahadur A, Mittal S, Malhotra N, Bhatt A. Predictive value of endometrial thickness, pattern and sub-endometrial blood flows on the day of hCG by 2D doppler in in-vitro fertilization cycles: A prospective clinical study from a tertiary care unit. Journal of human reproductive sciences. 2011; 4 (1): 29-33.

11. Contart P, Baruffi RL, Coelho J, Mauri AL, Petersen C, Franco Junior JG. Power Doppler endometrial evaluation as a method for the prognosis of embryo implantation in an ICSI program. Journal of assisted reproduction and genetics. 2000; 17 (6): 329-34.

12. Dechaud H, Bessueille E, Bousquet PJ, Reyftmann L, Hamamah S, Hedon B. Optimal timing of ultrasonographic and Doppler evaluation of uterine receptivity to implantation. Reproductive biomedicine online. 2008; 16 (3):368-75.

13. Ali S, Sophie R, Imam AM, et al. Knowledge, perceptions and myths regarding infertility among selected adult population in Pakistan: a cross-sectional study. BMC Public Health. 2011;11:760. Published 2011 Oct 4. doi:10.1186/14712458-11-760

14. Hilma $P$ and Binarwan $H$. Comparative Study between Mock Embryo Transfer Prior to The Treatment Cycle and Real Embryo Transfer in In Vitro Fertilization. ASPIRE Conference Proceedings The 6th Congress of the Asia Pacific Initiative on Reproduction (ASPIRE 2016), Volume 2016.

15. Hammadeh ME, Fischer-Hammadeh C, Ali KR. Assisted hatching in assisted reproduction: a state of the art. $J$ Assist Reprod Genet. 2010; 28 (2): 119-28.

16. Guzel AI, Erkilınc S, Ozer I, Tokmak A, Kurt Sahin A, Ugur M. Are uterine and ovarian artery Doppler velocimetry values 


\section{Samar Ramzy Ragheb, et al.,}

good pregnancy predictors in clomiphene citrate cycles?. Int J Fertil Steril. 2015; 9 (1): 41-6.

17. Kim MJ, Kim JJ, Kim SM. Endometrial evaluation with transvaginal ultrasonography for the screening of endometrial hyperplasia or cancer in premenopausal and perimenopausal women. Obstet Gynecol Sci. 2016; 59 (3):192-200.

18. Check JH, Dietterich C, Check ML, Katz Y. Successful delivery despite conception with a maximal endometrial thickness of $4 \mathrm{~mm}$. Clin Exp Obstet Gynecol. 2003; 30: 93-4.

19. Kolibianakis EM, Zikopoulos KA, Fatemi HM, Osmanagaoglu K, Evenpoel J, Van Steirteghem A, et al. Endometrial thickness cannot predict ongoing pregnancy achievement in cycles stimulated with clomiphene citrate for intrauterine insemination. Reprod Biomed Online. 2004; 8:115-8.

20. Zaidi J , Campbell S, Pittrof R and Tan S . Endometrial thickness, morphology, vascular penetration and velocimetry in predicting implantation in an in vitro fertiliza- tion program. Ultrasound Obstet Gynecol, 1995; 6: 191-198

21. Steer C, Mills C, Tan S. The cumulative embryo score ; a predictive embryo scoring technique to select the optimal number of embros to transfer in an invitro fertilization and embryo transfer programme. Hum. Reprod ; 1992 ,7,117-119.

22. Raine-Fenning N, Campbell B, Kendall N, Clewes J, Johnson I. Endometrial and subendometrial perfusion are impaired in women with unexplained subfertility, Human Reproduction, Volume 19, Issue 11, 1 November 2004, Pages 2605-2614

23. Abdel Wahab H, Salah D, Zain E, Abdelgany $M$ and Youssef $M$. Uterine artery Doppler and sub-endometrial blood flow in patients with unexplained recurrent miscarriage. Middle East Fertility Society Journal. 2011.

24. Alcazar J, Ruiz-Perez M. Uteroplacental circulation in patients with first-trimester threatened abortion. Fertil Steril; 2000;7 3: 130-135. 


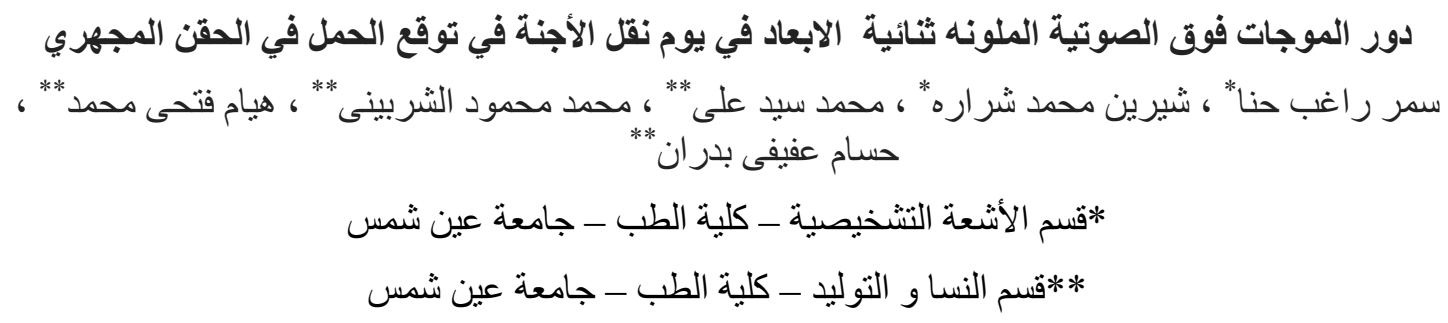

المقدمة : يشيع استخدام فحص بطانة الرحم بو اسطة الموجات فوق الصوتبة كإجر اء غير جراحي لتقييم تقبل بطانة

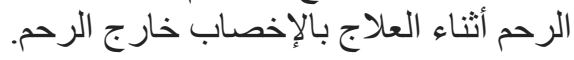

الهُف من البحث : لتقييم دور مؤشر النبض لتدفق الدم في الشريان الرحمي أثناء دورات الحقن المجهرى في التنبؤ

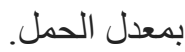

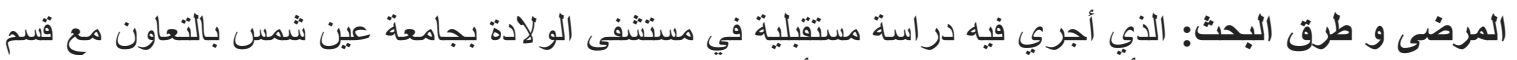

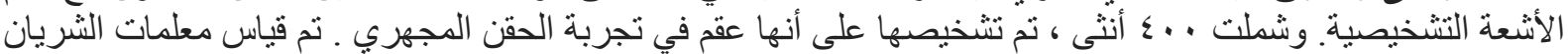

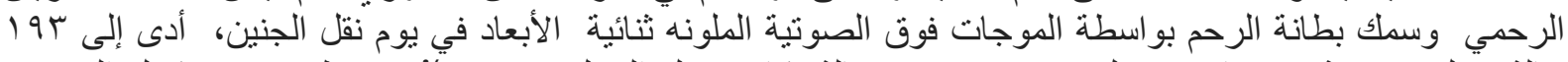

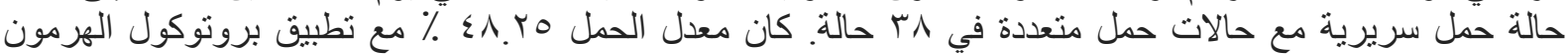

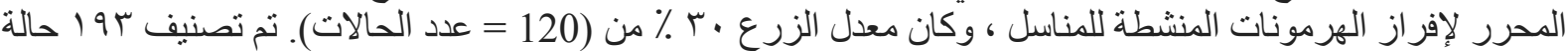

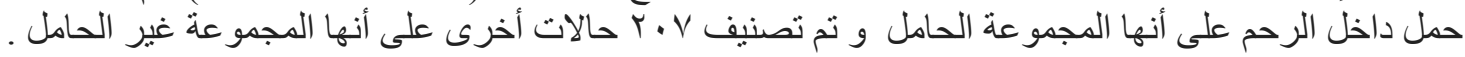

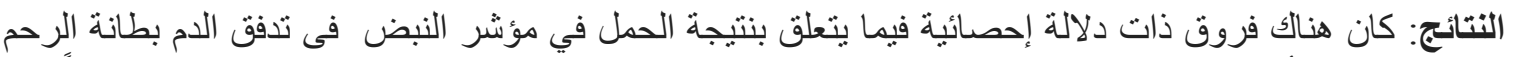

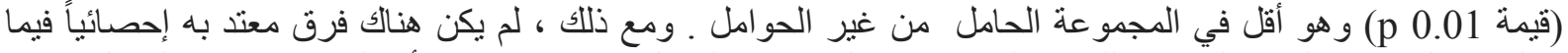

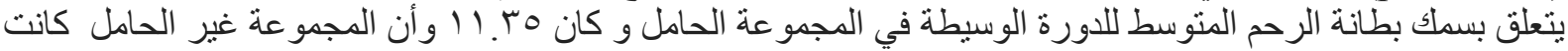

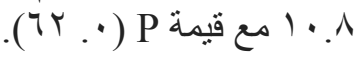
الخلاصة: أثنتت المرحلة المنوسطة من الإناث المصابة بالعقم غير المبرر أنها ذات قيمة في التنبؤ بمعدلات الحمل. 